\title{
Das opiniōes publicadas para as opiniōes postadas: os atalhos informativos e a internet nos temas internacionais
}

\section{From Printed to Posted Opinions: The Informational Shortcuts and the Internet on} International Issues

De las opiniones impresas a las publicaciones en internet: los atajos informativos y el uso de las redes sociales en los asuntos internacionales

Jonatas Torresan Marcelino ${ }^{1}$

DOI: $10.5752 /$ P.1809-6182.2020v17n2p20

\begin{abstract}
Resumo
$O$ artigo tem o objetivo de debater os efeitos das redes sociais e da internet nas capacidades informacionais da opiniáo pública e na conjuntura internacional. Será contextualizada a literatura referente aos atalhos cognitivos e capacidades informativas da opiniäo pública e como esses conceitos podem ser influenciados pela conjuntura contemporânea de crises globais.

Palavras-chave: Redes Sociais. Atalhos Informativos. Relaçôes Internacionais.
\end{abstract}

\begin{abstract}
The paper aims to explore effects of the internet and social network on informational capabilities of public opinion and on the international stage. The references discussed are focused on cognitive shortcuts and informational capabilities, taking into account how these concepts can be influenced by the current global crisis.

Keywords: Social Networks. Informational Shortcuts. International Relations.

\section{Resumen}

Este artículo discutirá los efectos de las redes sociales en las capacidades informacionales de la opinión pública y en la situación internacional. Se analizará la literatura relacionada a los atajos cognitivos y capacidades informativas de la opinión pública y cómo estos conceptos pueden ser influenciados por el contexto de crisis globales contemporáneas.

Palabras clave: Redes Sociales. Atajos Informativos. Relaciones Internacionales.
\end{abstract}

\footnotetext{
1 Jonatas Torresan Marcelino é Doutor em Relaçôes Internacionais pela Universidade de São Paulo (USP), Mestre em Relaçôes Internacionais pela Universidade do Estado do Rio de Janeiro (UERJ) e Bacharel em Comunicação Social (Habilitação em Jornalismo) pela Universidade Estadual Paulista (UNESP). Reside em São Paulo (SP), Brasil. Sua agenda de pesquisa está centrada na interação entre redes sociais, imprensa e relaçôes internacionais. ORCID: 0000-0002-1943-2933.
} 
A capacidade informacional da opinião pública $^{2}$ sobre temas internacionais é um problema central para a compreensão do ambiente no qual a política externa é desenvolvida. Zaller (2003) afirma que as limitações presentes na decodificação de assuntos políticos complexos para o cidadão comum são um consenso tanto na Psicologia quanto nas literaturas de Ciências Econômica e Política. Nesse sentido, Baum e Potter (2008) identificam uma linha comum entre as principais investigaçóes em opiniâo pública e política externa: a desvantagem informacional dos públicos na comparação com as elites da comunidade de política externa é parcialmente compensada pelos atalhos cognitivos (heuristic cues $^{3}$, no termo original), auxiliares na compreensão de informaçóes complexas do campo internacional.

De acordo com Popkin (1994), a racionalidade presente na informação escassa sobre temas políticos segue uma lógica de combinação de aprendizado e informaçóes de experiências passadas, cotidiano, mídias e campanhas políticas. No processo de comportamento eleitoral abordado pelo cientista político, ele afirma que o uso dos atalhos cognitivos informativos (informational shortcuts, no termo original) tem o objetivo de obter, simplificar e avaliar as informaçôes políticas disponibilizadas na mídia, que são trianguladas nas conversas em relacionamentos de confiança e de figuras políticas já

2 Opinião pública é um conceito difundido originalmente por Walter Lippman (1965), que afirma que as imagens de si e dos outros, em combinação com suas demandas, propósitos e relacionamentos, constituem as suas opinióes públicas. Key (1961), por sua vez, sustenta que a opinião pública é constituída pelas opiniōes individuais de pessoas físicas, as quais os governos creem ser prudente levar em consideração.

3 Baum e Potter (2008) definem heuristic cues como a capacidade do cidadão comum de analisar o ambiente político racionalmente com baixos volumes de informação. conhecidas pelo eleitor. Os atalhos cognitivos informativos são, portanto, os caminhos utilizados pelo público para decodificar os assuntos políticos complexos, com as finalidades de tomar decisões eleitorais e elaborar posicionamentos sobre temas sofisticados, de política doméstica ou internacional.

Powlick e Katz (1998) sustentam que a aquisição de informação factual é custosa, de forma que o público geral considera "irracional” construir um posicionamento político sofisticado sobre notícias externas remotas de seu cotidiano. Os autores salientam ainda que a construção de posicionamentos sobre temas internacionais e de política externa é dificultada pela ausência de contato pessoal com estrangeiros, inclusive em países desenvolvidos e multiculturais. Para Schmitt-Beck (2003), o alto custo de participação para a informação política também envolve variáveis como renda, tempo, motivação e autoconfiança no uso de atalhos cognitivos informativos mais sofisticados para a decodificação de assuntos políticos complexos. A partir da criação das redes sociais, esse cenário de desvantagem informacional entre elites e públicos pode ter sido afetado pela maior oferta e menor custo de informação.

Neuman et al (1992) afirmam que a conexão de cidadãos comuns com temas políticos domésticos e externos - via atalhos cognitivos informativos - ocorre de forma a interromper os acontecimentos de seu mundo privado, sendo, portanto, acidental, improvisada e desorganizada. Com a crescente dependência das mídias nas sociedades urbano-industriais desde os anos 1980, esse processo de interrupção se se aprofundou ainda mais posteriormente. As redes sociais, acessadas hoje com mais frequência do que os meios de comunicação offline dos anos 1980, tornaram esse cenário percebido 
no final dos anos 2000 ainda mais complexo. Sobretudo, porque as interrupçôes midiáticas passam a ser cada vez mais frequentes a partir dos smartphones e das redes sociais.

A definição de quais são os atalhos preferenciais dos públicos é objeto de debate na literatura, que apontam um, dois ou mais atalhos principais para acessar os temas externos:

\section{- Posicionamentos de políticos prefe-} renciais - Berinsky (2007) afirma que, na ausência de conhecimento sobre temas externos, os eleitores emulam os posicionamentos de seus políticos preferenciais como atalhos para temas internacionais, delegando aos representantes a tarefa de encontrar um posicionamento sobre temas que lhes são estranhos. Essa estratégia permite aos eleitores tomar decisóes racionais e coerentes sobre temas distantes e complexos. Berinsky (2007) afirma ainda que, na medida em que o nível de informação política é ampliado, os eleitores conseguem distinguir com mais clareza os posicionamentos conflitantes intra elites.

\section{- Políticos preferenciais e notícias -} Utilizando um modelo de comunicaçâo considerando as vias entre elites, grupos de interesse, políticos eleitos e a opinião pública, Powlick (1995) afirma que políticos e notícias na imprensa são vias mais utilizadas na compreensão de temas internacionais quando comparados a elites e grupos de interesse.

\section{- Preferências partidárias, notícias} e discurso das elites - Aldrich et al (2006) sustentam que, no caso específico de atalhos cognitivos para política externa, as preferências partidárias, as notícias e o discurso das elites são os caminhos mais utilizados. Eles salientam ainda que, na média, os cidadãos desinformados têm a capacidade de tomar decisóes políticas similares aos muito informados. Aldrich et al (1989) também afirmam que, apesar de informaçóes políticas escassas, os eleitores também têm a capacidade de diferenciar programas de política externa entre os candidatos por meio de seus atalhos cognitivos, e que essa diferenciação influencia na sua escolha de votos.

- Valores - Powlick e Katz (1998) afirmam que o público utiliza seus valores mais importantes como atalhos cognitivos para a formação de posicionamentos em questóes (issues) internacionais

A difusão da internet entre a sociedade civil nos anos 1990 e 2000 trouxe três novos fatores de relevo para esse debate. Em primeiro lugar, a disponibilidade de mais informação alterou a forma como os temas internacionais são cobertos pela imprensa. Baum (2003) sustenta que as hard news internacionais foram paulatinamente adaptadas para soft news, para que pudessem se encaixar melhor em talk-shows e telejornais, em uma mescla de temas complexos com entretenimento. De acordo com o autor, esse movimento nos Estados Unidos permaneceu mesmo após os atentados de $11 \mathrm{de}$ setembro de 2001.

O segundo ponto é a percepção de maior complexidade $^{4}$ da opinião pública em relação a temas externos, que tem um impor-

4 O imaginário de unidade da opinião pública tem raízes históricas na própria atitude dos governos ao longo da Guerra Fria. Cohen sinaliza que a burocracia da política externa nos Estados Unidos considerava a imprensa como a fonte primária da opinião pública e a utilizava como ferramenta de mensuração dos humores da população para balizar a tomada de decisóes de política externa (Cohen, 1963; 1995). 
tante marco em estudo conduzido por Risse-Kappen (1991). Investigando em perspectiva comparada os comportamentos das opiniōes públicas dos Estados Unidos, Japão, Alemanha Ocidental e França em relação a União Soviética, o autor divide a opiniáo pública entre: (1) opiniáo pública de massa; (2) attentive public, interessado em política de forma geral; (3) issue public, interessado em temas específicos. Em uma fase pré-difusão da internet mas já na Revolução Informacional, o autor já indica que uma elevada segmentação de interesses não se dá somente nas elites, conforme definido por Almond 5 na Guerra Fria, mas também entre o público geral. Essa divisão se aprofunda ainda mais adiante com a construção de comunidades digitais e clusters via redes sociais, que se constituem na prática como redes de perfis e páginas de portes desiguais entre diferentes países, que revelam interesses desiguais em temas externos.

O terceiro ponto diz respeito aos efeitos das mudanças tecnológicas provocadas pela internet em relação às mídias offline. Segundo Livingston e Bennett (2003), a chegada da internet provocou um aumento do volume de cobertura de notícias internacionais nas mídias, mas, por outro lado, reforçou a autoridade das fontes de informação governamentais em paralelo. No entanto, esse reforço das fontes governamentais se dá apenas na primeira fase da difusão da internet para o público, até meados dos anos 2000, quando está datado o início da difusão das grandes redes sociais conhecidas. Atualmente, os governos e a própria imprensa constituem dois entre muitos clusters de redes sociais nos quais as informaçôes políticas circulam.

\footnotetext{
5 Almond (1960) tipifica os públicos entre atentos e desatentos. A classificaçáo de Risse-Kappen (1991) eleva a complexidade dessa tipificação a partir dos issues.
}

Ou seja, a lógica de reforço da autoridade ${ }^{6}$ governamental nas coberturas em temas internacionais, sinalizada na Guerra Fria e continuada na primeira fase da internet, se dilui na medida em que os governos e a imprensa não são mais os atalhos cognitivos informativos principais para a compreensão de temas externos, mas as comunidades políticas e não-políticas em redes sociais nas quais os cidadãos conectados estão inseridos. Portanto, as discordâncias a respeito de temas políticos antes restritos às elites transbordam para uma opinião pública previamente segmentada em um sentido partidário, mas que passa a ser dividida a partir de um grande número de issues, materializados em diferentes clusters nas redes sociais.

$\mathrm{O}$ uso da internet pela sociedade civil em sua fase pré-redes sociais apresentava um otimismo influenciado pelo final da Guerra Fria e pelo auge da Globalização Liberal. Esse clima de otimismo continuaria à época do nascimento das redes sociais. A ideia central era a de que a internet seria um instrumento de aprofundamento da democracia liberal e de ampliação das liberdades civis por meio de novas ferramentas de deliberação.

Essa visão começa a mudar a partir dos vazamentos de dados do governo dos Estados Unidos (EUA) pelo Wikileaks (2010), que evidencia que a internet também pode ser uma ferramenta poderosa para questionar a atuação dos Estados nos planos doméstico e internacional. A percepção da internet como ferramenta poderosa é o combustível de revoltas urbanas turbinadas pelas redes sociais na década seguinte.

Os exemplos iniciais dessa nova visão da internet vêm do Norte da África e do Oriente Médio, onde ocorre a Primavera Árabe (2011),

\footnotetext{
6 Zaller e Chiu (2000) encontraram forte alinhamento entre posicionamentos de diferentes governos dos EUA e das mídias locais ao longo de 35 crises internacionais de 1945 a 1991.
} 
com destaques para a Tunísia e o Egito. Posteriormente, em 2013, o próprio Egito, a Turquia e o Brasil são palco de mais revoltas em grandes centros urbanos, com o denominador comum das redes sociais como canalizadores de organização e expressão desses movimentos. $\mathrm{Na}$ Europa e nos Estados Unidos, as manifestaçóes nas ruas passam a seguir essa lógica, embora tenham impacto político-institucional menos profundo na comparação com Egito, Turquia e Brasil.

Essas transformaçôes geram uma forte reação dos governos com relação à internet $\mathrm{e}$ às redes sociais no plano internacional. As reaçôes, no caso de regimes não democráticos, se dão pela tentativa de estabelecer limites no uso e nos conteúdos compartilhados via censura de redes sociais ou pela própria interrupção de serviços de internet em situaçóes pontuais - como ao redor de locais de protestos.

No caso das democracias, as próprias eleiçôes presidenciais e parlamentares em diferentes países ocidentais e latinos sinalizam novos rumos para diferentes cenários nas respectivas políticas domésticas, com implicações na distribuiçáo de preferências do eleitorado e da composição das principais forças partidárias nos parlamentos. Novas forças políticas, não alinhadas aos partidos mais tradicionais e centristas, ganham capilaridade rapidamente, com fundamental importância de redes sociais como Twitter e Facebook em suas estratégias eleitorais.

Consequentemente, os partidos e campos alvos dos protestos são enfraquecidos politicamente, durante e após os protestos, em diferentes eleiçôes. Além da piora do desempenho eleitoral, os governos de regimes democráticos têm mais restrições na implementação de medidas de contenção legais e de vigilância digital.
Essas restriçôes vêm da maior exposição das diferentes instituiçôes públicas nas redes sociais.

Com esses marcos, podemos identificar quatro tendências de crises que se apresentam na década de 2010: são as crises comunicacional, de convergência política, dos partidos políticos e da democracia liberal.

A crise comunicacional se dá a partir do advento da internet para a sociedade civil e das redes sociais. Mudam tanto a comunicação entre governo e cidadáos, quanto a comunicação dos próprios cidadãos entre si. A internet e as redes sociais são os ingredientes básicos de outras três crises intimamente relacionadas: convergência política, partidos centristas tradicionais e da própria democracia liberal.

Com relação à crise de convergência política, Da Empoli (2019) sinaliza que a política offline nas democracias liberais apresentava uma tendência centrípeta. Para a criação de um consenso majoritário, as mensagens políticas deveriam ser moderadas e segmentadas a categorias identitárias mais amplas - como sindicatos, estudantes, empresários. Essa dinâmica favorece em geral os candidatos e partidos centristas.

O autor indica que a chegada da variável Big Data muda radicalmente esse cenário. Em primeiro lugar, o Big Data torna possível a microssegmentação e a customização da mensagem política de forma precisa e individualizada. E, na era da política digital, o engajamento se dá primariamente pelo compartilhamento de conteúdos extremos e de forte apelo emocional.

$\mathrm{Na}$ prática, o comportamento de candidatos competitivos eleitoralmente muda. Antes do Big Data, competitivos eram centristas "moderados e preparados" nos termos das democracias liberais. Com o Big Data, os candi- 
datos competitivos devem-se comportar como pontos focais dos trending topics na política, se possível provocando-os e manipulando-os em benefício de seu espectro político. Ou seja, trabalhar as mensagens chave de seu espectro político em coerência com os temas do dia. Então, a crise de convergência política carrega a política do centro para os extremos do espectro como uma "força centrífuga" (DA EMPOLI, 2019).

Os principais perdedores nessa dinâmica centrífuga são os partidos centristas tradicionais das democracias liberais. Eles perdem poder conforme a política caminha para os extremos do espectro, reforçando o discurso de deslegitimidade das elites, conceito que ganha especial elasticidade nesse novo cenário. Essa elasticidade se dá na medida em que a deslegitimidade das elites é trabalhada pelos partidos antissistêmicos de forma a abarcar não somente os próprios partidos centristas, mas segmentos sociais considerados "elitistas", como universidades e o setor cultural.

Por fim, às três crises indicadas somam-se à outra já em curso entre as democracias liberais: a da queda de seus índices de confiança como a melhor forma de governo existente. A queda dos índices de confiança nas democracias liberais atinge tanto as democracias mais antigas (como, EUA, Reino Unido e França), como as democracias da chamada "terceira onda” após os anos 1980 (América Latina, Ásia e Leste Europeu), de acordo com dados da World Value Survey analisados por Moisés (2005) Cattenberg e Moreno (2005) e Moisés e Carneiro (2008).

$\mathrm{Na}$ conjuntura das quatro crises, Susskind (2018) sustenta que os "filtros informativos" se apoiam na confiança que o público deposita em terceiros para: (a) encontrar e reunir informaçôes; (b) escolher as relevantes de serem documentadas; (c) decidir a profundidade de contextualização e detalhamento necessária; (d) compartilhar com os possíveis interessados. Para o autor, os pressupostos deste trabalho dirigido aos públicos interessados em notícias são os de que as informaçôes recebidas são verdadeiras e hierarquizadas pela sua importância. Essas funçôes eram dominadas pela imprensa offline ao longo do Século XX, que dividia com o Estado a função de ser a principal via para que o público acessasse os distantes temas internacionais (SUSSKIND, 2018).

Susskind (2018) afirma ainda que, com as redes sociais, o Estado tenta avançar novamente em um território de construção da percepção pública de terceiros. Esse trabalho era atribuído a uma imprensa independente nas democracias liberais e hoje é disputado abertamente pelos agentes públicos - e também por outros atores, como Estados estrangeiros - nas redes sociais. A entrada do Estado como ator nas redes sociais não se dá de forma espontânea e planejada: os agentes públicos são sugados para essa dinâmica em virtude de crises sistêmicas, instrumentalizadas por atores externos para a sua desestabilização por motivos diversos.

Em outras palavras, as dinâmicas de percepção política pelo público para acessar temas internacionais passam por uma profunda transformação ao longo das duas primeiras décadas deste século. Muitos alicerces da construção da percepção política passam por rompimentos, segundo Da Empoli (2019). Elencaremos brevemente sete dessas quebras:

1. Quebra da intermediação informacional offline: As redes sociais demarcam o fim da intermediação informacional da imprensa offline em caráter de exclusividade. Para se tornarem relevantes, os veículos de comunicação formados 
em um mundo pré-internet devem se submeter aos novos parâmetros de interação/engajamento, internos às redes sociais e externos a eles mesmos.

2. Quebra da autoridade da fonte: No mundo offline, com discursos legitimados pelos filtros da imprensa e dos livros, havia uma hierarquização de fontes e de seus discursos. Com as redes sociais, o volume de engajamento em posts legitima mais uma opinião do que o seu próprio conteúdo. Em última análise, isso tem impacto direto não só na autoridade de fontes estatais, mas na de fontes científicas que utilizam evidências de investigaçôes para os debates públicos. Se o engajamento é menor, o discurso tem menor valor.

3. Quebra dos conteúdos comunitários: Além do critério de autoridade da fonte na comunicação online ter sido alterado, a customização das notícias (incluindo a customização de fake news) tem contribuído para a quebra de conteúdos comunitários. Diferentes campos políticos estáo cada vez mais presos em suas bolhas, com acesso a conteúdos desconectados dos da oposição.

4. Quebra do politicamente correto: Para Da Empoli (2019), a estratégia de comunicação da direita populista é "quebrar os códigos do politicamente correto" construídos pela esquerda e pelos liberais ao longo das últimas cinco décadas. Esse processo é acentuado pelas três quebras mencionadas anteriormente.

5. Quebra do espectro político: os novos partidos operam com uma lógica distinta das esquerdas e direitas nas democracias liberais do século XX. Nessa lógica, os findings a respeito de cada eleitor no Big Data têm mais relevância do que o espectro ideológico auto-atribuído ou socialmente atribuído a cada eleitor. Considerando o cenário no qual as definiçôes de esquerda e direita são marginalizadas pela direita populista, a nova estratégia política apontada por Da Empoli (2019) passa por uma nova divisão entre povo e elites, incluindo o contingente de revoltados de todos os espectros em seu campo. Isso também afeta a coerência dos conteúdos programáticos, antes submetidos ao espectro clássico de direita e esquerda, mas que agora são engolidos pelos tópicos que geram engajamento.

6. Quebra da convergência pelo Centro: Nas democracias liberais pré-digitais, a convergência dos candidatos "viáveis" de esquerda e direita ocorria pelo Centro do espectro político. A estratégia era o diálogo com um máximo de grupos sociais representativos. $\mathrm{Na}$ era do Big Data, os conteúdos mais extremistas geram mais engajamento e indicam com maior precisão os grupos-alvo, pela via dos algoritmos. Parte dessa convergência dos candidatos passava pela necessidade de comprovar experiência na administração pública e de compor uma equipe de governo que mesclasse competência técnica e boas conexões políticas para viabilizar o programa de governo. Essas vantagens comparativas anteriores passam a ser evidências de pertencimento às elites e são substituídas por outras características desejadas entre o eleitorado, dentre as quais estão a capacidade de gerar engajamento, a 
inexperiência administrativa e especialmente a falta de conexôes com as elites.

7. Quebra da Globalização Liberal: As "elites globalistas" são o principal alvo da nova direita, cujo objetivo em seu conjunto é interromper o processo de globalização nos moldes liberais e retornar a um sistema nacionalista de equilíbrio de poder entre potências.

$\mathrm{O}$ resultado de todas as quebras ocorridas ao longo da última década são as divisôes. São divididas as informaçóes, as realidades construídas socialmente, os objetivos em meio a essa realidade e os valores que motivam tais objetivos. A divisão das informaçôes recebidas se dá tanto pela via das informaçôes verídicas, mas ultra segmentadas por algoritmos, quanto pela via das fake news - já operantes ainda na Guerra Fria sob a alcunha de desinformação. Cada peça de informação (ou desinformação) constrói um quebra-cabeça da realidade cujo quadro difere cada vez mais do outro espectro político. Ou seja, a realidade deixa de ser compartilhada e passa a ser customizada. Susskind (2018) adiciona um problema extra a esse quadro de "política da pós-verdade": esse cenário tende a acentuar o problema e tornar os diferentes polos cada vez mais distantes.

Se antes a convergência política pelo Centro indicava os mesmos objetivos a serem atingidos pela esquerda ou pela direita no pós Guerra Fria (exemplo, o aprofundamento da Globalização Liberal), agora a distância entre os polos torna cada vez mais problemática a ideia de dialogar. Nesse contexto, os próprios valores sobre o que é um político ideal para ocupar cargos de liderança sofre uma divisão. Inexperiência administrativa e confronto ao sistema político estabelecido são qualidades para um polo, e defeitos para o outro.
Nessa conjuntura de crises, quebras e divisões, Susskind (2018) defende que os dados são poder. De acordo com ele, as entidades que controlarem os dados controlarão três fontes de poder no futuro: força (coerção), escrutínio e percepção de controle. Essas são fontes de poder porque cada vez mais uma gama maior de comportamentos humanos é transformada em dados, fato que deve ser acentuado futuramente com o $5 \mathrm{G}$ e a internet das coisas; e porque a forma como nós organizamos esses dados revela muito dos nossos valores políticos.

Dessa maneira, a posse de mais dados aumenta a probabilidade do uso desses dados para moldar preferências políticas de forma significativamente mais precisa do que os meios de comunicação de massa offline o conseguiram. A tese de Susskind (2018) é que, ao longo do tempo, tais poderes sobre os dados se concentrarão crescentemente nas mãos do Estado e de grandes corporaçôes tecnológicas.

A relevância da conjuntura internacional desta década de crises, quebras de paradigmas e divisionismos é precisamente essa: Estados e grandes corporaçôes tecnológicas estão em movimento para assumir o controle da maior gama de dados possível. Evidentemente, os Estados saíram atrás nessa corrida, sendo pegos de surpresa no início da década por movimentos sociais massivos e vazamentos de informaçóes muito sensíveis.

Portanto, essa foi a década da transição dos atalhos informativos dos públicos das mídias offline para as redes sociais online, transição esta que alterou de forma sensível o comportamento político das elites e dos públicos nos planos domésticos e global. A interação entre conjuntura internacional, atitudes políticas e a tecnologia na próxima década seguirá trazendo desafios para conhecer os diferentes caminhos trilhados por estes atores. 


\section{Referências}

ALDRICH, JH; GELPI, C; FEAVER, P; REIFLER, J; SHARP, KT. Foreign policy and the electoral connection. Annual Review of Political Science, v. 9, p. 477-502, 2006.

ALDRICH, JH; SULLIVAN, JL; BORGIDA, E; Foreign affairs and issue voting: Do presidential candidates waltz before a blind audience?. The American Political Science Review, v. 83, n. 1, p. 123-41, 1989.

ALMOND, G. The American People and The Foreign Policy. London-New York: Praeger, 1960

BAUM, MA. Soft News Goes to War: Public Opinion and American Foreign Policy in the New Media Age. Princeton,NJ: Princeton University Press. 2003.

BAUM, M; POTTER, P. The Relationships Between Mass Media, Public Opinion, and Foreign Policy: Toward a Theoretical Synthesis. Annual Review of Political Science, v. 11, p. 39-65, 2008.

BERINSKY, A. Assuming the costs of war: events, elites, and American public support for military conflict. Journal of Politics, v. 69, n. 4, p. 975-997, 2007.

CATTENBERG, G; MORENO, A. The individual bases of political trust: trends in new and established democracies. International Journal of Public Opinion Research, v. 18, n.1, p. 31-48, 2005.

COHEN, BC. The Press and Foreign Policy. Princeton, NJ: Princeton University Press, 1963.

COHEN, BC. Democracies and Foreign Policy: Public Participation in the United States and the Netherlands. Madison: University of Wisconsin Press, 1995

DA EMPOLI, G. Os Engenheiros do Caos. São Paulo: Vestígio, 2019

KEY, VO. Public Opinion and American Democracy. New York: Knopf, 1961.

LIPPMAN, W. Public Opinion. London: Collier-Macmillan, 1965.

LIVINGSTON, S, BENNETT, L. Gatekeeping, indexing, and live-event news: Is technology altering the construction of news? Political Communication, v. 20, n. 4, p. 363-380, 2003.
MOISÉS, J. A desconfiança nas instituições democráticas. Opiniáo Pública, v. 11, n. 1, p. 33-63, 2005.

MOISÉS, J; CARNEIRO, G. Democracia, desconfiança política e insatisfaçáo com o regime: o caso do Brasil. Opinião Pública, v. 14, n. 1, p. 1-42, 2008.

NEUMAN, R; JUST, MR; CRIGLER, AN. Common Knowledge: News and the Construction of Political Meaning. Chicago: University of Chicago Press, 1992.

POPKIN, SL. The Reasoning Voter: Communication and Persuasion in Presidential Campaigns. Chicago: University of Chicago Press, 1994.

POWLICK, PJ. The sources of public opinion for American foreign-policy officials. International Studies Quarterly, v. 39, n. 4, p. 427-451, 1995.

POWLICK, P; KATZ, AZ. Defining the American public opinion/foreign policy nexus. International Studies Quarterly, v. 42, n. 1, p. 29-61, 1998.

RISSE-KAPPEN, T. Public Opinion, Domestic Structure, and Foreign Policy in Liberal Democracies. Cambridge: World Politics, 1991.

SCHMITT-BECK, R. Mass communication, personal communication and vote choice: the filter hypothesis of media influence in comparative perspective. British Journal of Political Science, v. 33, n. 2, p. 233-259, 2003.

SUSSKIND, J. Future Politics. Oxford: Oxford University Press, 2018

ZALLER J, CHIU D. Government's little helper: U.S. press coverage of foreign policy crises, 1946-1999. In: NACOS, BL; SHAPIRO, RY; ISERNIA, P (eds.). Decisionmaking in a Glass House: Mass Media, Public Opinion, and American and European Foreign Policy in the 21st Century. New York: Rowman \& Littlefield. 2000. p. 61-84.

ZALLER, J. A new standard of news quality: burglar alarms for the monitorial citizen. Political Communication, v. 20, n. 2, p. 109-130, 2003. 